\title{
Suggestions for a Teacher Training Program for Inclusive Education in a Japanese University
}

\author{
Junichi Takahashi \\ Department of Developmental Disorders, National Institute of Mental Health, \\ National Center of Neurology and Psychiatry, Tokyo, Japan \\ Email: j_taka@ncnp.go.jp
}

Received June $3^{\text {rd }}$, 2013; revised July $3^{\text {rd }}$, 2013; accepted July $10^{\text {th }}$, 2013

\begin{abstract}
Copyright (C 2013 Junichi Takahashi. This is an open access article distributed under the Creative Commons Attribution License, which permits unrestricted use, distribution, and reproduction in any medium, provided the original work is properly cited.
\end{abstract}

\begin{abstract}
Inclusive education has been recently proposed in primary and secondary educations in many countries. Children who need special education support should be educated together with typically developing children in general classes. Although many studies have examined the effectiveness of inclusive education, researchers have pointed out that some general education teachers experience problems in their relationships with children who have disabilities such as developmental disorders and intellectual disabilities. In this paper, we review teacher training programs in a Japanese university and offer suggestions to enhance teachers' relationships with disabled children. In our discussion, we focused on adult attachment theory, which is an affective connection and interactions between self and others. First, we reviewed the importance of teachers' relationships with disabled children. Second, we reviewed attachment theories with respect to the quality of teacher-child relationships, and lastly, we proposed that adult attachment theory is a mediator in the quality of teacher-child relationships. We proposed a direction for the application of these conceptual assumptions to the teacher-training program for inclusive education in a Japanese university.
\end{abstract}

Keywords: Inclusive Education; Developmental Disorders; Intellectual Disability; Adult Attachment Theory; Teacher-Child Relationships

\section{Introduction}

In Japan, $0.6 \%(60,302)$ of all children in primary and secondary schools attended special support schools and $1.2 \%$ $(124,166)$ of all children attended special support classes in general schools in 2008 (MEXT: Ministry of Education, Culture, Sports, Science, and Technology). The educational system requiring compulsory education for children needing special education began in 1979. Thereafter, with all disabled children receiving compulsory education, the number of children who attend special support schools has continued to increase. This educational system would separate children with disabilities from regular schools. A portion of the School Education Act was revised in 2007 with regard to the educational system's support for children with special needs. The education for children with disabilities extended to the community in addition to services received at special support schools. These changes have been supported by efforts toward normalization and inclusive education.

Internationally, inclusive education is increasingly seen more broadly as a reform of educational systems (UNESCO, 2001). The efforts of government, school boards, principals, and teachers are needed to facilitate inclusive education. Specifically, teachers should be willing to acquire the knowledge and skills necessary to adapt their teaching to all children, including those with and without a disability (Pivik, McComas, \& Laflamme, 2002). However, some studies have pointed out problems with inclusive education. The instruction methods of general edu- cation teachers require adaptation for children with disabilities (i.e., those with intellectual disability, autism spectrum disorder, attention deficit hyperactivity disorder, dyslexia, and learning disability), because teachers must conduct measurements of children's behavior and their symptoms and develop intervention plans based on these symptoms (Koegel, Matos-Freden, Lang, \& Koegel, 2012). In this situation, teachers are challenged to establish positive relationships with children with disabilities. However, children with disabilities, such as autism spectrum disorder have difficulty with social interaction and are uninterested in interacting with others (Diagnostic and Statistical Manual of Mental Disorders, Fourth Edition, Text Revision; DSM-IV-TR, 2000). Since general education teachers have often had less training in techniques for working with disabled children, they have problems in these relationships. Although some previous studies have examined the effectiveness of teachers' relationships with disabled children, the investigations have been limited (Robertson, Chamberlain, \& Kasari, 2003). In particular, the findings of few studies on teachers' relationships with disabled children have been applied in university teachertraining programs (Koegel et al., 2012). In order to contribute to solutions to this problem, we reviewed the previous studies that examined teachers' relationships with children with disabilities. We focused on adult attachment theory (i.e., teachers' attachment style) in teacher-child relationships and provided directions for the application of knowledge about teachers' attachment styles to the teacher-training programs in a Japanese university. 


\section{Teacher-Child Relationships Affect Children's School Adjustment}

\section{Teachers' Relationships with Typically Developmental Children}

Positive teacher-child relationships in the early grades predict school success and adjustment of children in later grades (e.g., Hamre \& Pianta, 2001; Pianta \& Stuhlman, 2004). To examine the quality of teacher-child relationships, researchers frequently have adopted the questionnaire method by using the STRS (Student-Teacher Relationship Scale: Pianta, 2001). This questionnaire assesses the affective quality of caregiving relationships in primary and secondary education and is used to determine teachers' perceptions of their relationships with individual children. Previous studies have examined teacher-child relationships in primary and secondary schools (Baker, 1998, 2006; Birch \& Ladd, 1997, 1998; Howes \& Ritchie, 1999; Hughes, Cavell, \& Jackson, 1999; Pianta, 1999, 2001). These studies consistently indicated that close relationships with teachers are associated with positive school adjustment. Baker (2006) examined the influence of teacher-child relationships on school adjustment with 1310 elementary school students and found that the quality of teacher-child relationships was associated with academic indicators of school adjustment and success in formative elementary-school-aged and older students. Hughes et al. (1999) examined the influence of teacher-child relationship quality on children's aggression levels across 3 academic years. Behavioral descriptions of aggression included "picks on other children," "starts fights," "teases," "tells lies about others," and "excludes others from their group." Results showed that the teacher-child relationship could predict the developmental trajectory of aggressive children. The quality of the teacher-child relationship in the first academic year predicted teachers' ratings of aggression the next year. Less aggression was associated with positive teacher-child relationships in the next academic year.

\section{Teachers' Relationships with Disabled Children}

The importance of teacher-child relationships in general classes also applies to children with disabilities as a precondition for the children's quality of life and the reduction of problem behaviors (e.g., Hastings, 2005; Schuengel, Kef, Damen, \& Worm, 2010), as reported by many previous studies (Blacher, Baker, \& Eisenhower, 2009; Eisenhower, Baker, \& Blacher, 2007; Lang, Marlow, Goodman, Meltzer, \& Ford, 2013; Libbet, 2004; Mclntyre, Blacher, \& Baker, 2006; Robertson et al., 2003; Roeden, Maaskant, Koomen, Candel, \& Curfs, 2012). Eisenhower et al. (2007) showed that the quality of teacher-child relationships was lower for 6-year-old children with intellectual disability compared with typically developing children. Interestingly, Blacher et al. (2009) followed the Eisenhower et al. (2007) sample over the subsequent 2 years and examined whether the teacher-child relationship quality would be stable over time and whether the lower quality of teacher-child relationships among children with intellectual disability would continue over time. Results showed that the quality of teacherchild relationships was moderately stable with typically developing children, but it was not with intellectually disabled children. Specifically, lower quality teacher-child relationships con-tinued over the subsequent 2 years. Robertson et al. (2003) investigated the quality of teacher-child relationships with chil- dren with autism spectrum disorders. They found that children with autism spectrum disorder formed multidimensional relationships with their general education teachers to a degree that was modulated by the children's problem behavior and level of inclusion in the class. Importantly, the children's problem behavior was lessened when their general education teacher perceived positive relationships with them.

Previous studies found that adult attachment styles for teachers in primary and secondary schools modulated the teacherchildren relationships (Riley, 2009). Moreover, dimensions of the STRS questionnaire are based on concepts from attachment theory (Roeden et al., 2012). In our next topic, we review attachment theory and discuss the application of attachment theory to teacher-child relationships in inclusive education.

\section{The Influence of Teachers' Attachment Style on Teacher-Child Relationships}

\section{Attachment Theory in Typically Developing Children}

Attachment is an affective connection that is typically developed through interactions between children and a mother figure (Bowlby, 1969). Attachment relationships are based on an internal representation (IWM: internal working model) that represents how others will perceive and interact with an individual beyond early childhood. Children derive their sense of self-efficacy from their IWM: positive representations provide good self-efficacy, whereas negative representations provide poor self-efficacy. The magnitude of children's attachment has been measured by the Strange Situation Procedure (SSP: Ainsworth, Blehar, Waters, \& Wall, 1989). The SSP is an experimental design in which researchers observe children's behavior toward their parent after a short separation. According to the children's responses, they are generally classified into one of three attachment styles: secure, anxious, or avoidant. Children with a secure attachment style do not show resistant behaviors toward their parent after a short separation, whereas children with an anxious style desire proximity to their parent but simultaneously resist their parent's attempts at affection. Children with an avoidant style display avoidant behaviors and do not to seek the proximity of their parent. In general, estimates are that $65 \%$ of children have a secure attachment style, $15 \%$ have an anxious attachment style, and 20\% are avoidant (Van IJzendoorn, Goldberg, Kroonenberg, \& Frenkl, 1992).

\section{Attachment Theory in Children with Developmental Disorders and Intellectual Disability}

Regarding the attachment styles of children with developmental disorders (especially autism spectrum disorders), a meta-analysis (Rutgers, Bakermans-Kranenburg, Van IJzendoorn, \& Van Berckelaer-Onnes, 2004) indicated that children with autism spectrum disorder exhibit a secure attachment style to about the same degree as normally developing children. Using the SSP method, 53\% (40\% - 63\%) of children with autism spectrum disorder were classified as having a secure attachment style. On the basis of these results and in terms of attachment formation, children with an autism spectrum disorder might show the same development as normally developing children (Dissanayake \& Crossley, 1997).

In contrast, children with autism spectrum disorder and intellectual disability generally show a different attachment-style tendency (Carvill, 2001; Clegg \& Sheard, 2002; De Schipper, 
Stolk, \& Schuengel, 2006; De Schipper \& Schuengel, 2010; Schuengel, et al., 2010). Rogers, Ozonoff, \& Maslin-Cole (1991) indicated that differences in attachment style compared with typically developing children were caused by their level of cognitive ability. Similar indications were proposed by Schipper et al. (2006), who reported that attachment behavior varied depending on children's diagnoses. The risk of problem behavior in children with intellectual disability was about three times greater than that of typically developing children (Baker, Mcintyre, Blacher, Crnic, Edelbrock, \& Low, 2003). Both teachers and parents report many of the same problem behaviors and lack of social skills (Gagon, Vitaro, \& Tremblay, 1992). In children with intellectual disability, the form of attachment relationships with parents at home is likely to carry over to teacher-child relationships in school (O’Connor \& McCartney, 2006). Parents of children with intellectual disabilities generally have negative parent-child relationships. Thus, problem behaviors and early parent-child relationships in the home could predict the quality of teacher-child relationships in school (Eisenhower et al., 2007). Considering these indications, as reported by Rogers et al. (1991), the child's IQ level would mainly affect attachment-style differences between children with typical development, developmental disorders, and intellectual disabilities.

\section{Attachment Theory in Children Extended to Adult Attachment Theory}

Many studies have indicated that child attachment theory can be extended to adult attachment theory through the life span (e.g., Ainsworth, 1989; Hazan \& Shaver, 1987; Murphy \& Bates, 1997). In order to measure adult attachment, Hazan and Shaver (1987) developed the Attachment Style Questionnaire (ECR: Experiences in Close Relationships, Brennan, Clark, \& Shaver, 1998). This questionnaire is a self-report measure composed of three short paragraphs that correspond to the three attachment styles from the SSP method (i.e., secure, anxious, and avoidant). Bartholomew and Horowitz (1991) recently proposed an additional four categories that could be logically derived by combining two levels of "self-representation" (positive or negative) with two levels of "others-representation" (positive or negative) in adult attachment theory. The self-representation model reflects anxiety about closeness (i.e., whether the self is worthy of support), and the others-representation model reflects avoidance of intimacy (i.e., whether others are seen as trustworthy). Bartholomew and Horowitz (1991) conceptualized four styles based on these two axes: secure, preoccupied, fearful, and dismissing. The secure style has positive self- and others-representations. These individuals feel that the self is worthy and others are accepting, suggesting that secure individuals are neither anxious about abandonment nor avoidant of intimacy (Bartholomew \& Horowitz, 1991). Related to these characteristics, secure individuals display better mental health and positive self-perception (Kanemasa \& Daibo, 2003). Preoccupied individuals have a negative self-representation but positive others-representation. These individuals feel that the self is not worthy but that others are accepting. Dismissing individuals have a positive self-representation but negative othersrepresentation. These individuals sense that the self is worthy but that others are not accepting. In order to protect themselves against disappointment, dismissing individuals generally maintain independence and avoid close relationships with others
(Bartholomew \& Horowitz, 1991). Thus, although dismissing individuals show high self-esteem (similar to secure individuals), their social interactions are poor (Wilkinson \& Parry, 2004). Fearful individuals have negative self- and others-representations. These individuals feel that the self is unworthy of support and others are not generally accepting, suggesting that they are anxious about abandonment and rejection; thus, fearful individuals avoid intimacy. The Bartholomew and Horowitz (1991) results classified their sample into the four attachment styles as follows: secure (57\%), preoccupied (10\%), fearful (15\%), and dismissing (18\%).

\section{Adult Attachment Theory Underlying Social Interaction Ability Affects Teacher-Child Relationships}

Previous studies have generally indicated that adult attachment style affects social interaction ability (DiTommaso, Brannen-McNulty, Ross, \& Burgess, 2003; Hori \& Kobayashi, 2010; Kanemasa, 2005, 2007; Kanemasa \& Daibo, 2003; Takahashi, Tamaki, \& Yamawaki, in press; Tamaki \& Takahashi, in press). For example, Tamaki and Takahashi (in press) examined the relationship between adult attachment style and social interaction abilities in Japanese university students. Participants $(\mathrm{N}=$ 212, 110 men and 102 women) completed questionnaires on both attachment style and social skills. Results showed that those with dismissing and fearful styles had lower scores on many social-skill subscales compared with those who had secure and preoccupied styles. These results indicated that a negative others-representation attachment style affected to socialskill scores. Considering these indications, a teacher's attachment style is related to social interaction ability and may be an important factor in the teacher-child relationship. Specifically, attachment relationships are important and potentially protective mechanisms including children's behavior (Schipper et al., 2006). Thus, positive relationships with teachers seem to play a strong role for children with disabilities (Eisenhower, Baker, \& Blacher, 2007; Hamre \& Pianta, 2001). However, to the best of our knowledge, few studies have examined the effect of teachers' attachment styles on teacher-child relationships in inclusive education settings serving children with disabilities. In the next section, we discuss the application of our conceptual assumptions to teacher training programs.

\section{Applying Adult Attachment Theory to Teacher Training for Inclusive Education in a Japanese University}

In this section, we propose that adult attachment style should be considered in teacher training for inclusive education.

Teachers should have the ability to interact socially with children and to build good relationships with them (Eisenhower et al., 2007; Hamre \& Pianta, 2001). Considering that adult attachment theory underlies social interaction ability, secure individuals might more easily build positive teacher-child relationships compared with insecure (preoccupied, dismissing, and fearful) individuals because secure individuals hold positive self- and others-representations (i.e., self is worthy, and others are accepting), whereas insecure individuals hold negative selfor others-representations (i.e., preoccupied: self is not worthy, but others are accepting; dismissing: self is worthy, but others are not accepting; and fearful: self is unworthy of support, and 
others are not generally accepting). Positive self- and othersrepresentations are associated with good mental health (e.g., DiTommaso et al., 2003) and social interaction ability (e.g., Tamaki \& Takahashi, in press). Thus, a teacher's attachment style is important and is a potential protective mechanism in teacher-child relationships (Schipper et al., 2006).

Previous studies have indicated that adult attachment styles might vary depending on interpersonal relationships and circumstances through the life span, such as love relationships or major life transitions (e.g., Bowlby, 1988). Moreover, psychotherapy has led to significant changes toward increased secure attachment (e.g., Lawson, Barnes, Madkins, \& Francios-Lamonte, 2006; Travis, Binder, Bliwise, \& Horne-Moyer, 2001). For example, Travis et al. (2001) conducted time-limited dynamic psychotherapy (see Strupp \& Binder, 1984) and compared pre- and post-treatment attachment styles. Results showed that a significant number of clients changed from an insecure attachment style to a secure attachment style. Similar results were obtained by using group therapy (Lawson et al., 2006).

The teacher training course in a Japanese university is generally conducted as follows: second-year undergraduates receive instruction before visiting schools, third-year undergraduates receive instruction before they practice teaching, and fourthyear undergraduates receive instruction after they practice teaching. On the basis of adult attachment theory as proposed by previous studies (Bowlby, 1988; Lawson et al., 2006; Travis et al., 2001), we suggest measuring adult attachment style for university students enrolled in a teacher-training course and comparing the attachment styles between pre-teaching practice in the third undergraduate year and post-teaching practice in the fourth undergraduate year. Efforts might be needed to help students with insecure attachment styles to attain a secure style before they begin their teaching practice in their third year. A similar study method has been used in Japanese university teacher-training courses with regard to various viewpoints, such as teaching competence or motivation for becoming a teacher (e.g., Imae \& Shimizu, 1994; Koizumi, 2008). We propose that adult attachment style is also an important factor to be considered in a teacher-training program.

In this paper, we have identified potential problems with teacher-child relationships involving disabled children being served in inclusive education. We reviewed previous studies that examined the connection between teacher-child relationships and children's school adjustment and between teacher-child relationships and adult attachment style. From these indications, we pointed out the importance of teachers' attachment style in teacher-child relationships in inclusive education. Future research might provide evidence that teachers' attachment style is a potent factor in teacher-child relationships in inclusive education. Depending on the evidence of future studies, teachertraining programs for inclusive education can be facilitated by considering teachers' attachment styles.

\section{REFERENCES}

Ainsworth, M. D. S. (1989). Attachments beyond infancy. American Psychologist, 44, 709-716. doi:10.1037/0003-066X.44.4.709

Ainsworth, M. D. S., Blehar, M. C., Waters, E., \& Wall, S. (1978). Patterns of attachment. Hillsdale, NJ: Erlbaum.

American Psychiatric Association (2000). Diagnostic and statistical manual of mental disorders (4th ed.). Washington DC: American Psychiatric Association.
Baker, J. A. (1998). The social context of school satisfaction among urban, low-income, African-American students. School Psychology Quarterly, 13, 25-44. doi:10.1037/h0088970

Baker, J. A. (2006). Contributions of teacher-child relationships to positive school adjustment during elementary school. Journal of School Psychology, 44, 211-229. doi:10.1016/j.jsp.2006.02.002

Baker, B. L., Mcintyre, L. L., Blacher, J., Crnic, K., Edelbrock, C., \& Low, C. (2003). Preschool children with and without developmental delay: Behavior problems and parenting stress over time. Journal of Intellectual Disability Research, 47, 217-230. doi:10.1046/j.1365-2788.2003.00484.x

Bartholomew, K., \& Horowitz, L. M. (1991). Attachment styles among young adults: A test of a four-category model. Journal of Personality and Social Psychology, 61, 226-244.

doi:10.1037/0022-3514.61.2.226

Birch, S. H., \& Ladd, G. W. (1997). The teacher-child relationships and children's early school adjustment. Journal of School Psychology, 35, 67-79. doi:10.1016/S0022-4405(96)00029-5

Birch, S. H., \& Ladd, G. W. (1997). Children's interpersonal behaviors and the teacher-child relationship. Developmental Psychology, 35, 61-79.

Blacher, J., Baker, B. L., \& Eisenhower, A. S. (2009). Student-teacher relationship stability across early school years for children with intellectual disability or typical development. American Journal on Intellectual and Developmental Disabilities, 114, 322-339. doi:10.1352/1944-7558-114.5.322

Bowlby, J. (1969). Attachment and loss. London: Hogarth Press.

Bowlby, J. (1988). A secure base: Parent-child attachment and healthy human development. New York: Basic Books.

Brennan, K. A., Clark, C. L., \& Shaver, P. R. (1998). Self-report measurement of attachment: An integrative overview. In J. A. Simpson, \& W. S. Rholes (Eds.), Attachment theory and close relationships. New York: Guilford Press.

Carvill, S. (2001). Sensory impairments, intellectual disability and psychiatry. Journal of Intellectual Disability Research, 45, 467-483. doi:10.1046/j.1365-2788.2001.00366.x

Clegg, J., \& Sheard, C. (2002). Challenging behavior and insecure attachment. Journal of Intellectual Disability Research, 46, 503-506. doi:10.1046/j.1365-2788.2002.00420.x

De Schipper, J., C., Stolk, J., \& Schuengel, C. (2006). Professional caretakers as attachment figures in day care centers for children with intellectual disability and behavior problems. Research in Developmental Disabilities, 27, 203-216. doi:10.1016/j.ridd.2005.02.001

De Schipper, J., C., \& Schuengel, C. (2010). Attachment behavior towards support staff in young people with intellectual disabilities: Associations with challenging behavior. Journal of Intellectual Disability Research, 54, 584-596. doi:10.1111/j.1365-2788.2010.01288.x

Dissanayake, C., \& Crossley, S. A. (1997). Autistic children’s responses to separation and reunion with their mothers. Journal of Autism and Developmental Disorders, 27, 295-312. doi:10.1023/A:1025802515241

DiTommaso, E., Brannen-McNulty, C., Ross, L., \& Burgess, M. (2003). Attachment styles, social skills and loneliness in young adults. Personality and Individual Differences, 35, 303-312. doi:10.1016/S0191-8869(02)00190-3

Eisenhower, A. S., Baker, B. L., \& Blacher, J. (2007). Early studentteacher relationships of children with and without intellectual disability: Contributions of behavioral, social, and self-regulatory competence. Journal of School Psychology, 45, 363-383. doi:10.1016/j.jsp.2006.10.002

Gagnon, C., Vitaro, F., \& Tremblay, R. E. (1992). Parent-teacher agreement on kindergarteners' behavior problems. Journal of Child Psychology and Psychiatry, 33, 1255-1261.

Hamre, B. K., \& Pianta, R. C. (2001). Early teacher-child relationships and the trajectory of children's school outcomes through eighth grade. Child Development, 72, 625-638.

Hastings, R. P. (2005). Staff in special education settings and behavior problems: Towards a framework for research and practice. Educational Psychology, 25, 207-221.

Hazan, C., \& Shaver, P. (1987). Conceptualizing romantic love as an 
attachment process. Journal of Personality and Social Psychology, 52, 511-524.

Hori, M., \& Kobayashi, T. (2010). Association among adult attachment, social skills, and psychological adjustment for university students. Journal of School Mental Health, 13, 41-48.

Howes, C., \& Ritchie, S. (1999). Attachment organizations in children with difficult life circumstances. Development and Psychopathology, $11,251-268$.

Hughes, J. N., Cavell, T. A., \& Jackson, T. (1999). Influence of teacher-student relationship on childhood aggression: A prospective study. Journal of Clinical Child Psychology, 28, 173-184.

Imae, K., \& Shimizu, H. (1994). The effects of the teaching practicum on becoming a teacher. Japanese Journal of Educational Technology, 17, 185-195.

Kanemasa, Y. (2005). Early adult attachment styles, emotional regulation and sensitivity, and interpersonal stress coping: An examination of conceptual consistency in infant and early adult attachment styles. The Japanese Journal of Personality, 14, 1-16.

Kanemasa, Y. (2007). The relationships between early adult attachment styles and adjustment in friendships. The Japanese Journal of Social Psychology, 22, 274-284.

Kanemasa, Y., \& Daibo, I. (2003). Early adult attachment styles and social adjustment. The Japanese Journal of Psychology, 74, 466-473.

Koegel, L., Matos-Freden, R., Lang, R., \& Koegel, R. (2012). Interventions for children with autism spectrum disorders in inclusive school settings. Cognitive and Behavioral practice, 19, 401-412.

Koizumi, R. (2008). Do experiences of voluntary activity enhance perceived teaching competence of education major students: Comparison between graduates in teaching positions at the school and those in other jobs? Bulletin of Fukuoka University of Education, Part IV, Education and Psychology, 57, 49-54.

Lang, I. A., Marlow, R., Goodman, R., Meltzer, H., \& Ford, T. (2013). Influence of problematic child-teacher relationships on future psychiatric disorder: Population survey with 3-year follow-up. The British Journal of Psychiatry, 202, 336-341.

Lawson, D. M., Barnes, A. D., Madkins, J. P., \& Francios-Lamonte, B. M. (2006) Changes in male partner abuser attachment styles in group treatment. Psychotherapy: Theory, Research, Practice, Training, 43, 232-237.

Libbey, H. P. (2004). Measuring student relationships to school: Attachment, bonding, connectedness, and engagement. Journal of School Health, 74, 274-283. doi:10.1111/j.1746-1561.2004.tb08284.x

Mclntyre, L. L., Blacher, J., \& Baker, B. L. (2006). The transition to school: Adaptation in young children with and without intellectual disability. Journal of Intellectual Disability Research, 50, 349-361. doi:10.1111/j.1365-2788.2006.00783.x

Murphy, B., \& Bates, G. W. (1997). Adult attachment style and vulnerability to depression. Personality and Individual Differences, 22, 835-844. doi:10.1016/S0191-8869(96)00277-2

O’Connor, E., \& McCartney, K. (2006). Testing associations between young children's relationships with mothers and teachers. Journal of Educational Psychology, 98, 87-98. doi:10.1037/0022-0663.98.1.87

Pianta, R. C. (2001). The student-teacher relationship scale. Charlottesville, VA: University of Virginia.
Pianta, R. C., \& Stuhlman, M. W. (2004). Teacher-child relationships and children's success in the first years of school. School Psychology Review, 33, 444-458.

Pivik, J., McComas, J., \& Laflamme, M. (2002). Barriers and facilitators to inclusive education. Exceptional Children, 69, 97-107.

Riley, P. (2009). An adult attachment perspective on the studentteacher relationship \& classroom management difficulties. Teaching and Teacher Education, 25, 626-635. doi:10.1016/j.tate.2008.11.018

Robertson, K., Chamberlain, B., \& Kasari, C. (2003). General education teachers' relationships with included students with autism. Journal of Autism and Developmental Disorders, 33, 123-130. doi:10.1023/A:1022979108096

Roeden, J. M., Maaskant, M. A., Koomen, H. M. Y., Candel, M. J. J. M., \& Curfs, L. M. G. (2012). Assessing client-caregiver relationships and the applicability of the 'student-teacher relationship scale' for people with intellectual disabilities. Research in Developmental Disabilities, 33, 104-110. doi:10.1016/j.ridd.2011.08.027

Rogers, S. J., Ozonoff, S., \& Maslin-Cole, C. (1991). A comparative study of attachment behavior in young children with autism or other psychiatric disorders. Journal of the American Academy of Child \& Adolescent Psychiatry, 30, 483-488. doi:10.1097/00004583-199105000-00021

Rutgers, A. H., Bakermans-Kranenburg, M. J., Van Ijzendoorn, M. H., \& Van Berckelaer-Onnes, I. A. (2004). Autism and attachment: A meta-analytic review. Journal of Child Psychology and Psychiatry, 45, 1123-1134. doi:10.1111/j.1469-7610.2004.t01-1-00305.x

Schuengel, C., Kef, S., Damen, S., \& Worm, M. (2010). 'People who need people': Attachment and professional caring. Journal of Intellectual Disability Research, 54, 38-47. doi:10.1111/j.1365-2788.2009.01236.X

Strupp, H. H., \& Binder, J. L. (1984). Psychotherapy in a new key. New York: Basic Books.

Takahashi, J., Tamaki, K., \& Yamawaki, N. (in press). Autism spectrum, attachment styles, and social skills in university student. Creative Education.

Tamaki, K., \& Takahashi, J. (in press). The relationship between adult attachment style and social skills in terms of the four-category model of attachment style. Tohoku Psychologica Folia.

Travis, L. A., Binder, J. L., Bliwise, N. G., \& Horne-Moyer, H. L. (2001) Changes in clients' attachment styles over the course of timelimited dynamic psychotherapy. Psychotherapy, 38, 149-159. doi:10.1037/0033-3204.38.2.149

UNESCO (2001). The open file on inclusive education. Paris: UNESCO.

Van Ijzendoorn, M. H., Goldberg, S., Kroonenberg, P. M., \& Frenkl, O. J. (1992). The relative effects of maternal and child problems on the quality of attachment: A meta-analysis of attachment in clinical samples. Child Development, 63, 840-858. doi:10.1111/j.1467-8624.1992.tb01665.x

Wilkinson, R. B., \& Parry, M. M. (2004). Attachment styles, quality of attachment relationships, and components of self-esteem in adolescence. Proceedings of the 39th Australian Psychological Society Annual Conference. Melbourne: The Australian Psychological Society, 301-305. 